\title{
Erratum to: Development of bog-like vegetation during terrestrialization of polyhumic lakes in north-eastern Poland is not accompanied by ecosystem ombrotrophication
}

\author{
Paweł Pawlikowski $\cdot$ Ewelina Rutkowska $\cdot$ \\ Stanisław Kłosowski • Ewa Jabłońska • \\ Danuta Drzymulska
}

Published online: 4 February 2014

(C) Springer International Publishing Switzerland 2014

\section{Erratum to: Hydrobiologia \\ DOI 10.1007/s10750-013-1783-3}

Due to an unfortunate turn of events, the Acknowledgments section was omitted in the original publication causing a funding agency not to be properly acknowledged. The correct information is published here and should be treated as definitive by the reader.

Acknowledgments The research was financed by the Ministry of Science and Higher Education in Poland, project no. NN305085135.
The online version of the original article can be found under doi:10.1007/s10750-013-1783-3.

P. Pawlikowski $(\bowtie) \cdot$ E. Rutkowska $\cdot$ E. Jabłońska Department of Plant Ecology and Environmental Conservation, Institute of Botany, Faculty of Biology, University of Warsaw, Biological and Chemical Research Centre, ul. Żwirki i Wigury 101, 02-089 Warsaw, Poland e-mail: p.pawlikowski@uw.edu.pl

S. Kłosowski

Department of Environmental Protection and Modelling, The Jan Kochanowski University, ul. Świętokrzyska 15, 25-406 Kielce, Poland

D. Drzymulska

Department of Botany, Institute of Biology, University of Białystok, Świerkowa 20b, 15-950 Białystok, Poland 